\title{
Estratégias de comunicação como dispositivo para o atendimento humanizado em saúde da pessoa surda
}

\author{
Gicélia Barreto Nascimento ${ }^{1}$, Luciana de Oliveira Fortes², Themis Maria Kessler ${ }^{3}$
}

\section{RESUMO}

OBJETIVO: investigar a percepção de adultos surdos acerca das estratégias de comunicação estabelecidas com profissionais de saúde durante 0 atendimento. METODOLOGIA: Trata-se de uma pesquisa descritivo-exploratória, quanti-qualitativa. Amostra composta por 29 surdos, estudantes e professores de uma escola pública de educação especial e duas universidades federais do Rio Grande do Sul. RESULTADOS: Dos participantes, 59\% eram professores e 41\% eram estudantes. A idade variou entre 19 e 53 anos, sendo que $73 \%$ tinham perda auditiva neurossensorial de grau profundo, $86 \%$ nunca foram atendidos por profissional que soubesse Libras e $45 \%$ já desistiu do atendimento por dificuldades comunicativas. Dentre as dificuldades no acesso à saúde, $25 \%$ apontaram a sala de espera, $23 \%$ dificuldade em compreender explicações do profissional e $23 \%$ ausência de intérpretes. CONCLUSÃO: Foi possível perceber que existem estratégias comunicativas que podem promover cuidado e humanização no atendimento à saúde da pessoa surda.

Descritores: Surdez; Comunicação; Pessoal de Saúde.

\section{Communication strategies as a tool for humanizing health care for the deaf person}

\begin{abstract}
GOAL: to investigate the perception of deaf adults about the communication strategies established by health professionals during care. METHODOLOGY: it was conducted a descriptive/exploratory qualitative and quantitative research. Sample consisted of 29 deaf students and teachers from one public special school and two federal universities of Rio Grande do Sul. RESULTS: Of the participants, $59 \%$ were teachers and $41 \%$ were students. Age ranged between 19 and 53 years, and $73 \%$ had profound sensorineural hearing loss, $86 \%$ have never been assisted by a professional who knew Libras and $45 \%$ have dropped out of care by communication difficulties. Among the difficulties in access to health, $25 \%$ pointed out the waiting room, $23 \%$ found it difficult to understand the explanations of professionals and $23 \%$ lack of interpreters. CONCLUSION: It was possible to see that there are communication strategies able to promote care and humanization in the health care for deaf people.
\end{abstract}

Descriptors: Deafness; Communication; Health Personnel.

\footnotetext{
1,2 Mestre em Distúrbios da Comunicação Humana pela Universidade Federal de Santa Maria (UFSM), Santa Maria, RS, Brasil.

${ }^{3}$ Doutora em Programa de Pós-Graduação em Letras pela Universidade Federal de Santa Maria (UFSM), Santa Maria, RS, Brasil.
} 


\section{Introdução}

A comunicação é uma necessidade humana e pode ser definida como um processo por meio do qual se compartilham mensagens, ideias e sentimentos. Nas relações comunicativas, a audição desempenha uma função importante na percepção do mundo das coisas e das relações sociais ${ }^{1}$.

A ausência desse sentido é um dos fatores que desencadeiam distúrbios da comunicação, pois não ouvir dificulta a conversação por meio da linguagem oral, determinando a necessidade de se recorrer a variadas estratégias, visando a uma expressão e compreensão mais apropriadas da linguagem durante as trocas comunicativas, tanto pelos sujeitos surdos quanto pelos interlocutores ouvintes ${ }^{2}$.

Dessa maneira, adotar algumas estratégias de comunicação em situação de conversação é uma importante ferramenta de assistência ao sujeito surdo. Pois durante a consulta, os profissionais de saúde precisam orientá-los acerca do diagnóstico e tratamento, cujos resultados podem ser comprometidos pela não compreensão das partes envolvidas3.

Portanto, a questão da inclusão social referente ao atendimento de pessoas com deficiência auditiva, nos serviços de saúde, se estabelece como fator essencial da qualidade do serviço prestado. Enquanto que a falta de comunicação inviabiliza um atendimento humanizado3.

Entende-se a humanização do cuidado em saúde como sendo um conjunto de conhecimentos, processos e métodos usados na área da saúde. A mesma emprega a oferta de dispositivos e de tecnologias para fortalecer os diversos setores da saúde e da comunidade atendida. Os recursos tecnológicos, acesso, acolhimento e vínculo devem estar presentes na relação estabelecida entre trabalhadores e usuários para que as ações de saúde sejam mais acolhedoras, ágeis e resolutivas. Para que isso ocorra, o atendimento em saúde deveria estar baseado em um acolhimento dialogado, representado pela valorização do encontro. Nesse encontro "o profissional ouve e discute com o usuário, na tentativa de identificar suas necessidades e de saber o modo melhor de resolvê-las"4.

Os surdos, quando vão para locais públicos como, por exemplo, os setores de saúde e, principalmente, os consultórios de profissionais de saúde, deparam-se não apenas com uma limitação na autonomia, mas também com a redução da privacidade, pois, geralmente, vão acompanhados por familiares para que sejam interpretadas as suas consultas ${ }^{5}$. Por não fazer uso da língua, oral o surdo acaba ficando separado e/ou isolado, tendo seus conhecimentos sobre sua saúde ou saúde em geral prejudicados ou incompletos ${ }^{6}$.

Apesar de suas dificuldades de comunicação com as pessoas com quem convive, o surdo tenta se comunicar através dos meios possíveis e que estão ao seu alcance como: gestos, desenhos, escrita, e, dependendo do seu nível de treinamento, pode realizar leitura labial ${ }^{7}$. Por conseguinte, o profissional que recebe um surdo para atendimento em saúde deveria estar atento às singularidades comunicativas de que esse indivíduo necessita para, então, possibilitar de maneira humanizada a atenção em saúde voltada para essa pessoa.

A partir do exposto, este estudo tem como objetivo investigar a percepção de adultos surdos acerca das estratégias de comunicação estabelecidas com profissionais durante 0 atendimento em saúde. Também buscou verificar sugestões de estratégias comunicativas que possam facilitar o acesso à saúde pelo sujeito surdo visando possibilitar a humanização do atendimento.

\section{Metodologia}

A pesquisa em questão é de caráter descritivo-exploratório, quanti-qualitativa. Considera-se este molde metodológico como sendo o mais apropriado para a execução deste estudo, pois busca voltar-se para o aprofundamento da compreensão de um fenômeno social e do seu universo de significados. Além disso, a pesquisa descritiva adota como objetivo primordial a descrição das características de determinada população ou fenômeno, já a exploratória tem como objetivo proporcionar maior familiaridade com o problema ${ }^{8}$.

Para a efetivação desse estudo foram seguidas as normas éticas obrigatórias para pesquisas, sendo aprovado pelo Comitê de Ética em Pesquisa de Instituição de ensino Superior sob o número 0394.0.243.000-10.70. Como possíveis riscos ou desconforto, considera-se como um leve desconforto o tempo disponível para responder ao 0 instrumento de coleta de dados, aproximadamente 35 minutos para os surdos que aceitaram auxílio em língua de sinais. Como benefícios, compreende que conhecer as estratégias de comunicação e aprimorá-las constitui-se em uma importante ferramenta de acessibilidade e qualidade na assistência à saúde de sujeitos surdos. 
Como critérios de inclusão, os participantes deveriam ser usuários de serviço público de saúde; ter perda auditiva autodeclarada; ter nível de escolaridade de ensino superior completo ou em andamento e ter assinado o Termo de Consentimento Livre e Esclarecido (TCLE).

Com o intuito de solicitar autorização para a realização da coleta de dados, foi realizado contato com coordenadores dos seguintes setores: a diretoria de uma escola especial; a vice-reitoria de duas instituições de ensino superior, e, também com a coordenadoria do curso de Letras/Libras de uma das instituições de ensino superior.

Dessa maneira, amostra do presente estudo foi constituída inicialmente por 70 sujeitos surdos, dentre estudantes e professores de uma escola pública de educação especial e de duas universidades federais do estado do Rio Grande do Sul. Porém, como não houve retorno de todos os questionários, participaram desta amostra 29 surdos.

Para a coleta de dados, foram utilizados questionários entregues aos participantes em seus ambientes de estudo ou trabalho, conforme a sua preferência. Para aqueles que aceitaram a mediação em Língua Brasileira de Sinais (Libras), uma das pesquisadoras, bilíngue, auxiliava-os a responder o questionário. Porém, quando essa não estava presente, eram disponibilizados intérpretes para auxiliá-los, sempre respeitando o princípio da imparcialidade para que não houvesse uma possível indução das respostas dos participantes. O questionário continha 16 questões, abertas e fechadas, e foi construído visando investigar aspectos relacionados à comunicação entre profissionais ouvintes da área de saúde e pacientes surdos.

As questões de 1 a 4 abordaram o atendimento em saúde e as dificuldades encontradas pelo sujeito surdo ao procurar um serviço de saúde. As questões de 5 a 12 são referentes às estratégias de comunicação que possibilitam a compreensão do profissional ouvinte e o entendimento do sujeito surdo; também sobre as estratégias mais comumente usadas pelo surdo; as que facilitam, dificultam, promovem a autonomia e respeitam a privacidade do sujeito surdo.

As questões de 13 a 15 são referentes às adaptações ambientais e linguísticas que os sujeitos surdos avaliam ser necessárias para o atendimento em saúde. A última questão (16) faz referência às sugestões para facilitar 0 acesso à saúde, a fim de promover um atendimento de qualidade ao sujeito surdo.

Para análise, os dados foram tabulados em planilha, no programa Microsoft Excel 2010 e representados na forma de percentuais do total. As respostas das questões abertas foram agrupadas em categorias, por meio de uma leitura repetida das mesmas, identificação das argumentações presentes nos discursos dos sujeitos e reconhecimento das ideias convergentes, fazendo relação com a bibliografia disponível.

\section{Resultados}

Dos 29 sujeitos surdos que participaram da pesquisa, 48\% correspondem ao gênero masculino e $52 \%$ ao feminino, ambos com idade entre 19 e 53 anos. Aamostra foi constituída por $59 \%$ de professores e $41 \%$ de estudantes universitários.

Destes, a maioria $(73 \%)$ tinha perda auditiva neurossensorial de grau profundo ${ }^{1}$, sendo que $76 \%$ eram bilíngues, na qual a língua de sinais foi referida como sua primeira língua (L1) e a língua portuguesa escrita a sua segunda língua (L2). Relacionado ao uso de recursos tecnológicos, como Aparelho de Amplificação Sonora Individual (AASI) e/ou uso de Implante Coclear (IC), 79\% já fizeram uso de AASI, sendo que, no momento em que o estudo foi realizado, $90 \%$ não usavam mais o aparelho auditivo. Em contrapartida, nenhum participante da pesquisa era implantado.

O Aparelho de Amplificação Sonora Individual (AASI), utiliza uma tecnologia digital com diversos recursos. O AASI proporciona aos usuários a percepção dos sons com qualidade sonora, melhorando a compreensão de fala ea comunicação da pessoa com perda auditiva ${ }^{11}$. Já o Implante Coclear (IC) é um recurso tecnológico efetivo na re(habilitação) auditiva de indivíduos com perda auditiva neurossensorial de grau severo e profundo. O IC permite a estimular o nervo coclear, transmitindo os estímulos ao córtex cerebral. Ele substitui parcialmente as funções da cóclea, transformando a energia sonora em sinais elétricos. Diferente do AASI, o IC é colocado por meio de um procedimento cirúrgico, compreendendo uma parte externa junto ao osso do crânio, atrás da orelha, sob a pele, e uma parte interna posicionado dentro da cóclea ${ }^{12,13}$. Relacionado à percepção de fala, o IC é um recurso mais eficiente comparado com o AASI.

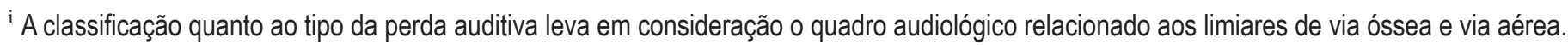
A perda auditiva é classificada como neurossensorial quando o limiar ósseo é maior que $15 \mathrm{dbNA}$, o limiar aéreo é maior que $25 \mathrm{dbNA} \mathrm{e} \mathrm{a} \mathrm{dife-}$ rença entre as vias área e óssea é de até $10 \mathrm{dbNA}$. Em geral, esse tipo de perda acomete a orelha interna ou o nervo coclear ${ }^{9}$. Já a classificação quanto ao grau da perda auditiva é realizada através dos limiares das frequências de 500, 1000 e $2000 \mathrm{~Hz}$. A perda auditiva é classificada como profunda quando os níveis audiométricos são iguais ou superiores a $71 \mathrm{dbNA}{ }^{10}$.
} 
A Figura 1 ilustra os sujeitos surdos que afirmaram ter desistido de procurar um serviço de saúde por falta de intérprete ou de outra pessoa ouvinte que pudesse intermediar a comunicação com o profissional da área. Bem como, os participantes que referiram já terem sido atendidos por algum profissional que soubesse Libras para se comunicar com 0 paciente. Verificou-se que a maioria afirmou nunca ter sido atendido por um profissional da área de saúde que soubesse Libras e que já desistiu de comparecer ao serviço por dificuldades comunicativas.

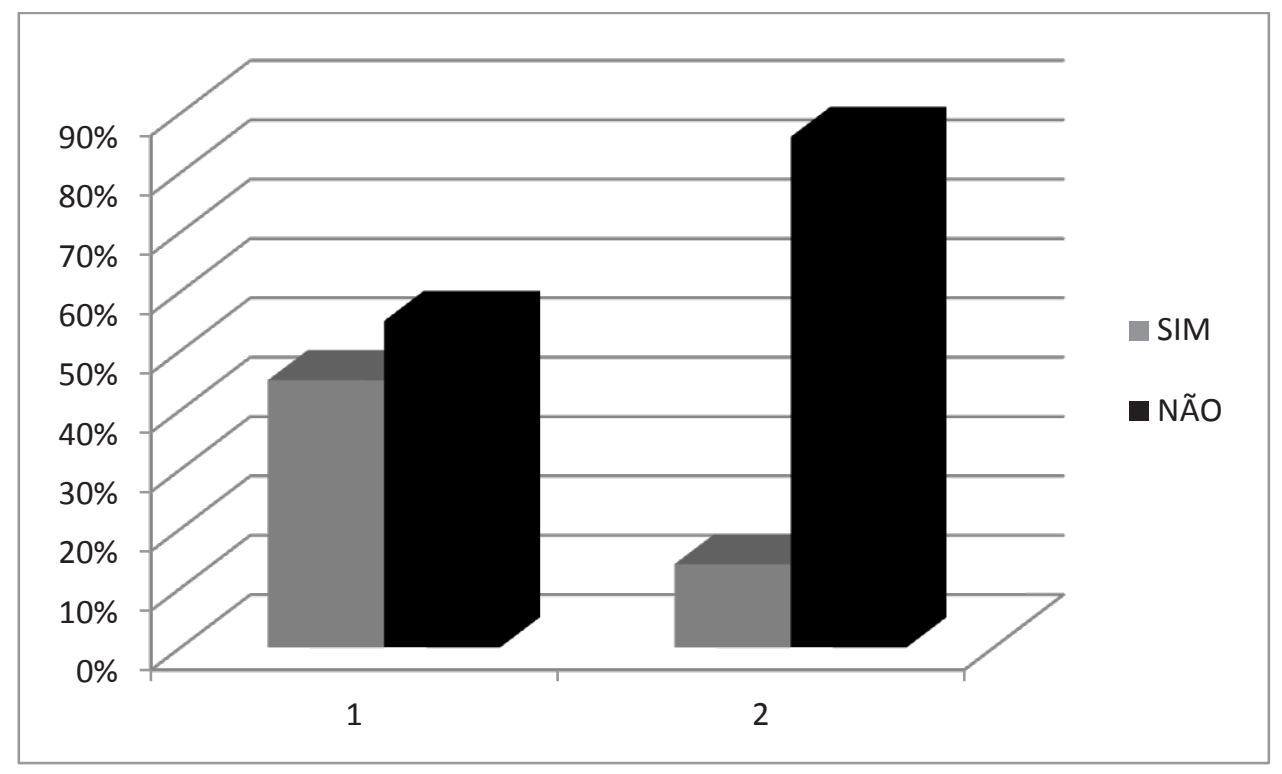

Figura 1: Desistência do atendimento por falta de intérpretes ou mediador (1); Registro de atendimento ao usuário surdo por profissional que sabia Libras (2).

A Figura 2 ilustra as dificuldades de comunicação referidas pelos surdos ao procurar atendimento nos serviços de saúde. Verificou-se que a maioria dos participantes referiu como maior dificuldade a comunicação com atendentes na sala de espera. Principalmente para entender quando são chamados para o atendimento.

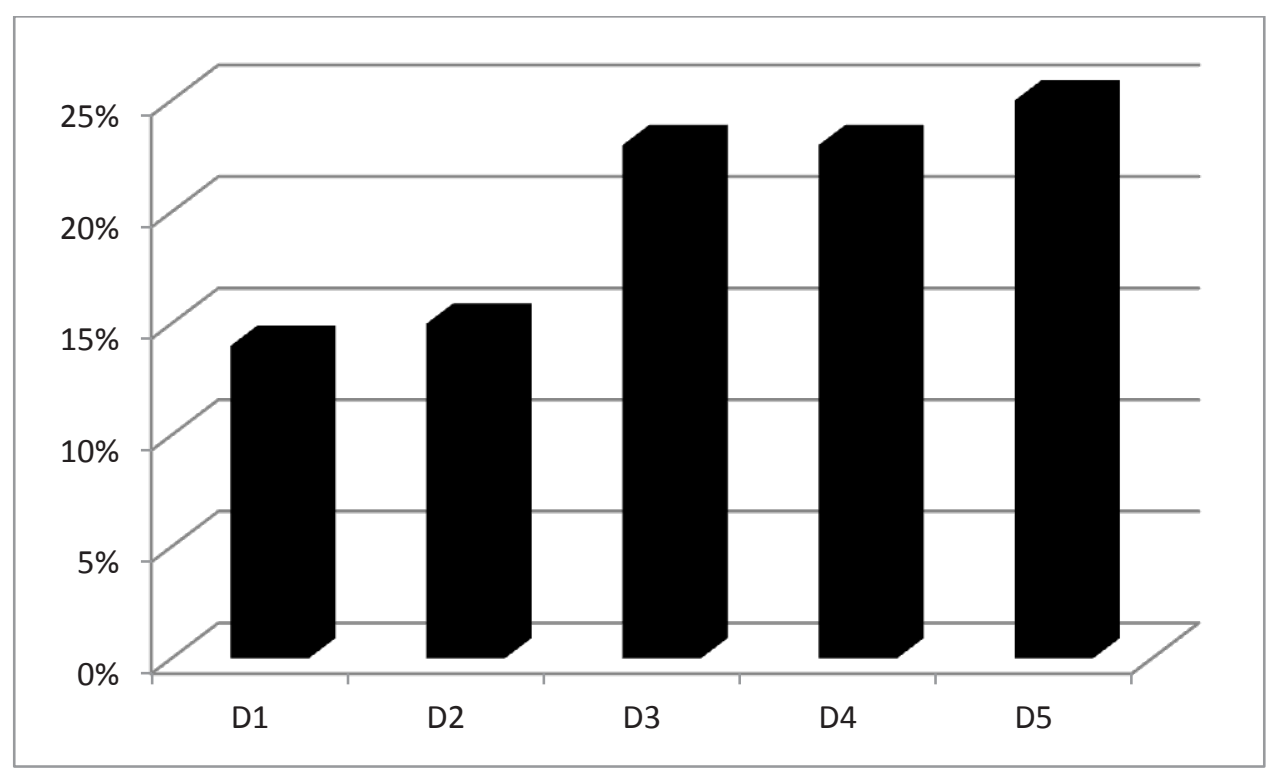

Figura 2: D1: problemas de comunicação durante exames e procedimentos; D2: dificuldades em agendar as consultas por telefone; D3: dificuldades para compreender explicações do profissional acerca do diagnóstico e tratamento; D4: ausência de intérpretes de Libras; D5: dificuldades presentes na sala de espera para se comunicar com atendentes e entender quando são chamados para 0 atendimento.

Já a Tabela 1 representa em percentual, quais as estratégias comunicativas utilizadas pelos profissionais de saúde no diálogo com o surdo. Pode-se observar que a estratégia mais utilizada pelos profissionais foi a comunicação verbal-oral, o que acabava dificultando o atendimento destes usuários. 
Tabela 1- Estratégias comunicativas utilizadas pelos profissionais de saúde que dificultam o diálogo com o paciente surdo

\begin{tabular}{c|c}
\hline Estratégias & $\%$ \\
\hline Comunicação verbal-oral & 34 \\
\hline Língua portuguesa escrita & 19 \\
\hline Leitura labial & 17 \\
\hline Acompanhante ouvinte & 11 \\
\hline Mímica/gestos & 9 \\
\hline Desenhos & 6 \\
\hline Figuras & 2 \\
\hline Libras & 2 \\
\hline
\end{tabular}

Relacionado às respostas apresentadas pelos sujeitos do estudo, sobre as estratégias que eles utilizam para se fazer compreender pelos profissionais, o que aparece em comum em seu discurso é que faziam uso da língua portuguesa em sua modalidade escrita e necessitavam do intérprete de Libras para mediar o atendimento.

Como sugestão para facilitar o atendimento e o cuidado em saúde, promovendo a acessibilidade e a humanização, foi citado no discurso dos surdos: a importância do intérprete e da própria Libras sendo utilizada no espaço de saúde.

Portanto, os surdos sugeriram, em seus relatos, que fossem contratados intérpretes para ficar disponíveis nas repartições públicas, auxiliando no processo de comunicação e interação do sujeito surdo e profissionais ouvintes. Desde a comunicação com a secretária para marcar consulta como para auxiliar nos exames e durante as consultas.

\section{Discussão}

A privação auditiva traz impactos negativos na vida de um indivíduo, comprometendo sua comunicação e inserção social. Não ouvir afeta a capacidade do indivíduo em compreender as informações que lhes são oferecidas socialmente, pois vivemos em um mundo sonoro. Além dos aspectos sociais essa privação pode levar a consequências biológicas e psicológicas ${ }^{14,15}$.

Nesse estudo, observou-se o impacto da privação auditiva no atendimento em saúde, visto que $75 \%$ dos participantes tinham perda auditiva neurossensorial de grau profundo, o que comprometia a comunicação com profissionais ouvintes da área de saúde. Mesmo sendo amplamente conhecido que essa privação sensorial repercute na conversação com as pessoas ao utilizar a língua oral em conversas formais e informais, bem como atender ao telefone, torna-se uma atividade extenuante para as pessoas surdas ${ }^{15}$, os profissionais de saúde ainda priorizam a fala para dialogar com esses pacientes.

Chama atenção o fato de que apesar de $79 \%$ dos participantes já terem feito uso de AASI, 90\% não utiliza mais tal recurso tecnológico como ferramenta de acessibilidade. Esse fato pode ser justificado pelo próprio histórico da saúde pública brasileira, no que diz respeito à habilitação e reabilitação auditiva por meio do uso do aparelho auditivo. Por muito tempo sustentou-se a prática da "doação" de próteses auditivas, que eram realizadas nos postos de saúde por profissionais da assistência social ${ }^{14}$.

Dessa maneira, para receber o aparelho auditivo era necessário apenas apresentar o diagnóstico da perda auditiva pelo médico otorrinolaringologista. Assim, os indivíduos que apresentavam tal diagnóstico recebiam o aparelho sem ter realizado uma avaliação para selecionar a prótese mais adequada para sua realidade, nem eram acompanhados em seu processo de adaptação ${ }^{14}$.

Apesar de essa prática ter deixado de existir há algum tempo, provavelmente ela era realizada na época em que os participantes desta pesquisa receberam seus diagnósticos auditivos, visto que apresentam idade entre 19 e 53 anos. Evidentemente isso, somado a outras dificuldades, pode tê-los levado ao abandono das próteses auditivas.

0 índice de 45\% dos surdos que desistiram de comparecer ao atendimento em saúde pode estar relacionado ao fato de os mesmos dependerem de uma pessoa para mediar sua comunicação com o profissional ouvinte. Como este profissional não sabe Libras, pois $86 \%$ dos usuários afirmaram nunca terem consultado com profissional que utilizasse essa língua, o cuidado e o encontro em saúde ficam prejudicados.

O surdo depende também da disponibilidade que os ouvintes têm em poder acompanhá-lo às consultas. A principal razão dessa dependência é a reduzida possibilidade de dialogar para compreender as instruções do profissional, por não dominarem a língua oral e pela ausência de um intérprete de Libras ${ }^{5}$. Assim, o adiamento da procura por atendimento pode causar sofrimento ao surdo e/ou agravamento do seu quadro, comprometendo sua qualidade de vida. Além de gerar complicações na relação profissional-usuário, abalar a confiança no profissional de saúde e comprometer a aderência ao tratamento ${ }^{16}$. 
Também foi verificado, dentre as dificuldades de comunicação encontradas pelos surdos durante 0 atendimento nos serviços de saúde, que $25 \%$ destes apontaram a sala de espera como sendo a primeira barreira de acesso. Isso mostra que, antes mesmo do encontro com o profissional, já há dificuldades na interação linguística. Tal obstáculo se apresenta já no contato com o atendente para confirmar a presença no atendimento, bem como para compreenderem que estão sendo chamados para entrarem na sala da consulta.

Constatou-se em outra pesquisa que os surdos se sentem discriminados por ficar muito tempo aguardando para serem atendidos, pois não escutam seus nomes ao serem chamados, demonstrando assim, a importância do atendente em saúde avisar o profissional de saúde sobre a presença de um surdo na sala de espera ou então, de ter painel eletrônico com senhas, para que o surdo possa acompanhar quando chegar a sua vez de ser atendido ${ }^{17}$.

Além da sala de espera, também foram apontadas dificuldades para compreender as explicações do profissional de saúde e a falta do intérprete para mediar a comunicação entre esse profissional ouvinte e seu paciente surdo, em um percentual de $23 \%$ cada.

Essa não disponibilidade de intérpretes nos serviços é considerada uma dificuldade de acesso à saúde. Esse dado também foi encontrado em um estudo, em que os surdos se queixavam da dificuldade para encontrar intérpretes disponíveis e qualificados para acompanhá-los ao atendimento em saúde, bem como para atuar nesse ambiente ${ }^{17}$.

Essas dificuldades apontadas pelos sujeitos da pesquisa ferem o direito do surdo de alcançar assistência humanizada em saúde. Pois se compreende a humanização do sistema de saúde como valorização da dignidade humana; respeito à vida, com ênfase na relação ética entre o usuário e o profissional de saúde. Nessa relação, deve-se preservar a autonomia das pessoas e garantir que elas tenham acesso à informação sobre sua própria saúde ${ }^{18}$.

Dessa maneira, a comunicação possui um papel fundamental na humanização da atenção à saúde. É importante enfatizar que a humanização do atendimento não se refere apenas ao resgate do que é mais bonito no humano. Mas a possibilidade de resgatar nos profissionais de saúde, de uma forma mais inteira e coerente, as suas dimensões comunicativas. Os profissionais da saúde precisam compreender que suas habilidades comunicativas perpassam as verdades de serem capazes de se relacionarem com as pessoas a sua volta. Além disso, melhorar a comunicação com o usuário significa conquistar o melhor de si mesmo, significa colocar a atenção em dimensões que muitas vezes passam despercebidas ${ }^{19}$.

Este estudo mostrou que um dispositivo que pode ser utilizado no atendimento humanizado da pessoa surda é o emprego de estratégias comunicativas. Essas possibilitam a assistência à saúde desses indivíduos, promovendo 0 cuidado com garantia de direitos. Entretanto, os participantes da pesquisa avaliaram que as estratégias comunicativas utilizadas pelos profissionais de saúde dificultam o seu acesso ao sistema de saúde. Dentre essas, destacam-se a comunicação verbal-oral (34\%); a língua portuguesa em sua modalidade escrita (19\%) e a leitura labial (17\%).

As estratégias de comunicação constituem um conjunto de determinadas atitudes que funcionam como agentes facilitadores para que a informação seja mais facilmente recebida visual ou auditivamente ${ }^{20}$. Porém, 0 uso de estratégias comunicativas inadequadas, na relação profissional ouvinte-usuário surdo, acaba dificultando ao invés de promover o diálogo ${ }^{16,21}$. Dentre elas, os médicos falarem ao paciente enquanto escrevem, não possibilitando ao surdo 0 uso da estratégia da leitura labial; médicos chamarem o paciente oralmente, esquecendo-se de que se trata de um surdo ${ }^{21}$.

Estudos mostram que o uso de estratégias comunicativas como a comunicação verbal-oral e a leitura labial pode comprometer o encontro usuário-profissional de saúde ${ }^{17,22}$. Isso ocorre porque surdos sentem dificuldades em entender a fala do profissional de saúde, visto que esses geralmente não se preocupam em evidenciar os movimentos articulatórios para a possível realização da leitura labial, pois falam rápido demais ou usam termos técnicos de difícil compreensão por leigos ${ }^{17}$. Além disso, a leitura labial pode gerar problemas específicos, devido ao fato de o sujeito surdo ter que manter foco constante naquele com quem se comunica porque qualquer mudança na posição do profissional de saúde pode levar à perda de informações ${ }^{22}$.

Já o uso da língua portuguesa, em sua modalidade escrita, pode ser um recurso de difícil utilização, pois, para muitos surdos a escrita representa uma segunda língua, e, como tal, pode representar dificuldades de domínio ${ }^{3}$.

Ao verificar as sugestões de estratégias comunicativas para facilitar o acesso à saúde do surdo, foi unanime nos discursos dos participantes a presença do intérprete e o uso de Libras no sistema de saúde.

É inegável que a presença do intérprete de Libras favorece a comunicação entre surdos e ouvintes. Assim, no cenário da saúde, o intérprete é considerado uma estratégia de comunicação que facilita o entendimento entre o profissional e o usuário ${ }^{21,23,24}$. Entretanto, ele não é a solução para os problemas da acessibilidade dos surdos aos serviços de saúde, visto que, alguns aspectos podem comprometer 0 atendimento como as questões éticas que exigem as diversas situações na área da saúde. Também pode gerar ansiedade no paciente em relação aos aspectos confidenciais da sua saúde, além de dificuldades em transmitir aos surdos questões específicas como termos relacionados às especialidades e linguagem técnica que, muitas vezes, não é acessível ao intérprete ${ }^{24}$. 
Porém, existem algumas estratégias comunicativas que podem auxiliar os profissionais de saúde a se comunicar de maneira eficaz com o usuário surdo, quando o intérprete estiver presente durante o atendimento. Dentre estas: abordar diretamente o intérprete uma única vez, apenas para agradecer sua disponibilidade em acompanhar o usuário; colocar 0 intérprete ao lado e ligeiramente atrás do surdo para que ambos sejam vistos simultaneamente; falar sempre diretamente com o usuário e não com o intérprete; manter as mãos sempre longe da face, especialmente da boca; evitar expressões específicas da área ou termos técnicos, pois muitas vezes são difíceis de traduzir e perguntar sempre ao surdo se ele está compreendendo o que está sendo dito25.

Referente ao uso da Libras, autores ${ }^{26,27}$ entendem ser a estratégia que promove a inclusão do surdo no serviço de saúde, bem como garante acesso aos princípios norteadores do Sistema Único de Saúde (SUS) de equidade, integralidade e universalidade ${ }^{26}$. Além de ser uma ferramenta que garantiria 0 atendimento humanizado aos usuários desta modalidade comunicativa. $O$ fato de o profissional de saúde não ter domínio da Libras é uma barreira para interagir com o usuário surdo, pois esta língua é um instrumento importante no atendimento dessas pessoas. Entretendo, nesses casos, os profissionais da saúde frequentemente não compreendem a língua do seu paciente ${ }^{24}$.

No Brasil, no ano de 2005, foi aprovado o Decreto $n^{0} 5.626$, que, em seus capítulos VII e VIII, trata da garantia de direitos à saúde das pessoas surdas ou com deficiência auditiva. Tal Decreto estabelece que pelo menos $5 \%$ dos funcionários, servidores, e empregados das unidades dos serviços públicos devem ser capacitados para uso e interpretação da Libras ${ }^{28}$.

Um estudo investigou a comunicação dos funcionários de uma unidade de saúde com pacientes surdos, buscando analisar o cumprimento do decreto №. 5.626. Os resultados do estudo mostraram que a maioria $(80 \%)$ dos funcionários atendiam usuários surdos, mas relataram não se sentirem preparados para atendê-los, pois não sabiam Libras (92,5\%). 0 estudo concluiu que havia um despreparo dos funcionários no atendimento dos pacientes surdos. Além disso, 0 Decreto № 5.626, embora aprovado desde 0 ano de 2005, ainda não estava sendo cumprido ${ }^{27}$.

A qualidade do atendimento, bem como a humanização da saúde não fazem sentido sem a necessidade de lançar um olhar sobre a comunicação. Sem a intenção de ser inteiro quando se está com o usuário, sem ter a capacidade de perceber o outro não há qualidade nem atendimento humanizado ${ }^{12}$. É preciso que gestores e profissionais da saúde compreendam que o cuidado em saúde se estabelece no encontro com o usuário, que se faz com a valorização da sua singularidade e suas particularidades comunicativas.

\section{Considerações Finais}

O presente estudo apontou algumas dificuldades enfrentadas pelos surdos, participantes deste estudo, ao procurarem os serviços de saúde que remetem a fatores como a ausência de intermediação durante a consulta, ausência da Libras nos serviços de saúde para possibilitar o diálogo do usuário com os profissionais e uso inadequado das estratégias de comunicação.

Também se verificou a indicação de necessidade da presença de um intérprete durante o atendimento à saúde, possibilitando inferir que o surdo não está alcançando uma comunicação efetiva, necessitando, assim, dessa mediação. Enquanto os intérpretes não são disponibilizados no sistema de saúde, o surdo deixa de exercer a sua autonomia, tendo seu direito à saúde violado. 0 mesmo depende de amigos e familiares para acompanhá-lo nas consultas, deixando de procurar atendimento quando estes não estão disponíveis.

Por meio deste estudo, também foi possível perceber que a estratégia de comunicação mais apontada como a que promoveria o cuidado no atendimento à saúde da pessoa surda, assim como a humanização do atendimento seria o uso da Libras no serviço de saúde. No momento em que as instituições de saúde implantassem uma assistência bilíngue, tornaria possível aos surdos ter mais amplo acesso à saúde. Consequentemente, menos surdos desistiriam do atendimento, pois alcançariam maior independência ao procurar assistência. 


\section{Referências Bibliográficas}

1. Pagliuca LMF, Fiúza NLG, Rebouças CBA. Aspectos da comunicação da enfermeira com o deficiente auditivo. Rev Esc Enferm USP. 2007; 41 (3): 411-8.

2. Stefanelli M. Comunicação com paciente: teoria e ensino. São Paulo: Robe; 1993.

3. Chaveiro N, Barbosa MA, Porto CC. Revisão de literatura sobre 0 atendimento ao paciente surdo pelos profissionais da saúde. Rev Esc Enferm USP. 2008; 42 (3): 578-83.

4. Coelho MO, Jorge MSB. Tecnologia das relações como dispositivo do atendimento humanizado na atenção básica à saúde na perspectiva do acesso, do acolhimento e do vínculo. Ciênc. saúde colet. 2009; 14(1): 1523-31.

5. Marin MC, Goés RA. Experiência de pessoas surdas em esferas de atividade do cotidiano. Cadern CEDES. 2006; 26(69): 231-49.

6. Dizeu LCTB, Caporali SAA. Língua de sinais constituindo o surdo como sujeito. Rev Educ Soc. 2005; 26(91):583-97.

7. Rosa CG, Barbosa MA, Bachion MM. Comunicação da equipe de enfermagem com deficiente auditivo com surdez severa: um estudo exploratório. Rev Eletr Enfe [periódico na internet]. 2000 [acesso em janeiro de 2014]; 2(2): [aproximadamente 5 p.]. Disponivel em: http://www.fen.ufg.br/revista/revista2_2/melita.html.

8. Gil AC. Como elaborar projetos de pesquisa. $5^{\text {a }}$ ed. São Paulo: Atlas; 2010.

9. Momensohn-Santos TM, Russo ICP. Prática da Audiologia Clínica. $7^{a}$ ed. São Paulo: Cortez; 2009.

10. Russo ICP, Pereira LD, Carvallo RMM, Anastásio ART. Encaminhamentos sobre a classificação do grau de perda auditiva em nossa realidade. Rev Soc Bras Fonoaudiol. 2009;14(2):287-8.

11. Lessa KM, Ferreira MIDC. Aplicabilidade das medidas de satisfação em usuários de aparelho de amplificação sonora individual: revisão sistemática. Distúrbios Comun. 20014; 26(4): 809-14.

12. Albernaz PL. History of cochlear implants. Braz J Otorhinolaryngol. 2015; 81(2):124-5.

13. Hilgenberg MAS, Cardoso CC, Caldas FF, Tschiedel RS, Deperon TM, Bahmad F. Hearing rehabilitation in cerebral palsy: development of language and hearing after cochlear implantation. Braz J Otorhinolaryngol. 2015;81(3):240-7.

14. SILMAN S, et al. Próteses auditivas: um estudo sobre seu benefício na qualidade de vida de indivíduos portadores de perda auditiva neurossensorial. Rev Dist Com [periódico na internet]. 2004 [acesso em janeiro de 2014]; 16:(2): 153-165. Disponível em: http://revistas.pucsp.br/index.php/dic/article/view/11635/8361

15. ALLAN L, KELLY-CAMPBELL RJ. Origins and Pawns Scales: A Pilot Study Assessing Perception of Control in Adults with Hearing Problems. Commun Disord Deaf Stud Hearing Aids. [periódico da internet]. 2013 [acesso em janeiro de 2014]; 1(1): [aproximadamente 8 p.]. Disponível em: http://www.esciencecentral.org/journals/origins-and-pawns-scalesa-pilot-study-assessing-perception-of-control-in-adults-with-hearing-problems-\%20JCDSHA.102.pdf

16. CASTRO SS, PAIVA KM, CESAR CLG. Dificuldades na comunicação entre pessoas com deficiência auditiva e profissionais de saúde: uma questão de saúde Pública. Rev Soc Bras Fonoaudiol. 2012; 17(2): 128-34.

17. CARDOSO AHA, RODRIGUES KG, BACHION MM. Perception of persons with severe or profound deafness about the communication process during health care. Rev. Latino-Am. Enfe. 2006; 14(4):553-60.

18. VAITSMAN J, ANDRADE GRB. Satisfação e responsividade: formas de medir a qualidade e a humanização da assistência à saúde. Ciênc. saúde colet. 2005; 10(3): 599-613.

19. SILVA MJP. O papel da comunicação na humanização da atenção à saúde. Rev. Bioética. 2002;10(2): 73-88.

20. RONDINA C, MATAS CG. Neuropatia Auditiva: estudo de caso. Acta - AWHO. 2006; 24(1):10-7.

21. COSTA LSM, et al. $O$ atendimento em saúde através do olhar da pessoa surda: avaliação e propostas. Rev Bras Clin Med. 2009; 7: 166-170.

22. BOTELHO, P. Educação inclusiva para surdos: desmistificando pressupostos. In: SEMINÁRIO INTERNACIONAL SOCIEDADE INCLUSIVA, 1, 2007. Belo Horizonte. Anais eletrônicos... Belo Horizonte: PUC Minas. 2007. Disponível em: <http://www.sociedadeinclusiva.pucminas.br/anaispdf/educsurdos.pdf> Acesso em: 10 nov. 2011.

23. CHAVEIRO N, BARBOSA MA. Assistência ao surdo na área de saúde como fator de inclusão social. Rev Esc Enferm USP. 2005; 39(4): 417-22.

24. CHAVEIRO N, et al. Atendimento à pessoa surda que utiliza a língua de sinais, na perspectiva do profissional da saúde. Cogitare Enferm. 2010;15(4):639-45.

25. LIEU CC, et al. Communication Strategies For Nurses Interacting with Deaf Patients. MEDSURG Nursing. 2007; 16(4): $239-45$. 26. JUNIOR RU, SANTOS DAS. Utilização da língua brasileira de sinais no atendimento aos surdos / deficientes auditivos como forma de humanização da enfermagem. Rev Virt Cult Sur Diver. [periódico da internet] 2009. [acesso em janeiro de 2014]; 1(1): [aproximadamente 7p.]. Disponível em: <http://www.editora-arara-azul.com.br/revista/compar4.php>. 
27. Magrini AM, Santos TMM. Comunicação entre funcionários de uma unidade de saúde e pacientes surdos: um problema? Distúrb Comum. 2014; 26(3): 550-8.

28. BRASIL. Decreto No 5.626, de 22 de Dezembro de 2005. Regulamenta a Lei no 10.436, de 24 de abril de 2002Dispõe sobre a Língua Brasileira de Sinais - Libras. 7. Barnett S. Communication with deaf and

\section{Gicélia Barreto Nascimento}

Endereço para correspondência - Departamento de Fonoaudiologia , Av. Roraima, $n^{\circ}$ 1000, CEP: 97105-900, Bairro: Camobi, Santa Maria, RS, Brasil.

E-mail: giceliabarreto89@yahoo.com.br

Lattes: http://lattes.cnpq.br/1233892396053837

Luciana de Oliveira Fortes - lucifortes@yahoo.com.br

Themis Maria Kessler - tkessler@terra.com.br

Enviado em 09 de agosto de 2014. Aceito em 09 de novembro de 2015. 
